\title{
PRODUÇÃO DO ESPAÇO URBANO DA SERRA-ESPÍRITO SANTO: estratégias recentes da construção imobiliária
}

\author{
Prof. Dr. Carlos Teixeira de Campos Júnior \\ Universidade Federal do Espírito Santo - UFES \\ Av. Fernando Ferrari, s/nº - Goiabeiras, CEP 29060-900, Vitória, Espírito Santo, Brasil \\ Tel: (55 27) 3324.2303 - ctcampos@gmail.com \\ Thalismar Matias Gonçalves \\ thalismargeo@yahoo.com.br
}

\begin{abstract}
RESUMO
Neste trabalho abordamos as recentes estratégias da construção imobiliária no espaço metropolitano da Grande Vitória $(\mathrm{RMGV})$. A atenção se voltou para as transformações do espaço urbano do município de Serra-ES, cuja dinâmica urbana esteve vinculada, historicamente, à expansão periférica da metrópole a partir dos anos 1970. Desse modo, as formas de produção imobiliária se articulavam, sobretudo, à reprodução da população com menos rendimentos, como os loteamentos populares e conjuntos habitacionais. Nos últimos anos, o município é palco privilegiado de investimentos do setor imobiliário, materializados em novas formas espaciais, como os condomínios fechados horizontais e verticais. Na dinâmica imobiliária da metrópole, Serra emerge como nova frente de atuação do capital imobiliário, que se fundamenta na promoção de um novo produto para o mercado capixaba, os condomínios fechados e sua imagem associada à segurança, acesso à natureza etc. A atuação da produção imobiliária capitalista no município é marcada por novas relações promovidas por grandes incorporadoras, com capital aberto em bolsa, que estabelecem "parcerias" com as empresas locais.
\end{abstract}

Palavras-chave: Região Metropolitana da Grande Vitória, construção imobiliária; condomínios fechados.

\begin{abstract}
This paper approaches the recent strategies of building construction in the metropolitan area of Vitoria (RMGV). It focuses on the transformations of urban space in the municipality of Serra-ES, whose urban dynamics was related historically to the peripheral expansion of the metropolis since 1970. Thus, the forms of housing construction were articulated, above all, with the reproduction of the lower income population, such as lots and housing for the working class. In recent years, the city is a privileged stage for real estate investment materialized in new spatial forms, such as horizontal and vertical condominiums. In the real estate dynamics of the metropolis, Serra emerges as another front in the performance of real estate capital, which is based on promoting a new product in the State of Espírito Santo market, gated communities and image associated with security, access to nature etc. The activity of capitalist building production in the city is marked by new relations promoted by large corporations, publicly traded on the stock exchange, which establish partnerships with local companies.
\end{abstract}

Key words: Grande Vitoria Metropolitan Region, building, condominiums.

\section{RÉSUMÉ}

Dans ce travail on prend en compte les stratégies récentes de la construction immobilière dans l'espace métropolitain de la Grande Vitória (RMGV), dans l'État de l'Espírito Santo. Notre attention se tourne vers les transformations de l'espace urbain de la commune de Serra, dont la dynamique urbaine a été liée, historiquement, à l'expansion périphérique de la métropole à partir de 1970 . Ainsi, les formes de production immobilière s'attachaient, principalement, à la reproduction de la population qui reçoit moins de revenus, comme les lotissements et les logements populaires. Ces dernières années, la commune est un domaine privilégié d'investissement du secteur immobilier matérialisé dans de nouvelles formes de l'occupation de l'espace, comme les copropriétés horizontales et verticales. Dans les dynamiques immobilières de la métropole, Serra émerge comme un autre front dans l'exécution du capital immobilier, basé sur la promotion d'un nouveau produit sur le marché de l'État de l'Espirito Santo, les copropriétés et leur image associée à la sécurité, l'accès à la nature, etc. Le rôle de la production immobilière capitaliste dans la commune est marqué par de nouvelles relations promues par les grandes sociétés, cotées à la bourse, l'établissement de «partenariats» avec les entreprises locales.

Mots-clés: Região Metropolitana da Grande Vitória; construction immobilière; condominiums fermés.

\section{INTRODUÇÃO}

A proposta de trabalho é realizar uma reflexão sobre as recentes mudanças observadas no processo de produção e apropriação do espaço urbano de Serra-ES (Figura 1), município que faz parte da Região Metropolitana da Grande Vitória (RMGV) ${ }^{1}$. Historicamente, a dinâmica urbana de Serra esteve associada à expansão periférica da metrópole da Grande Vitória, com a consolidação 
do processo de industrialização a partir da segunda metade da década de 1970. Assim, parte do território do município, de um lado, foi utilizada como suporte para a atividade industrial e, por outro, como lócus para a reprodução da população com menos rendimento, que chegava aos milhares à Grande Vitória nos anos 1970 e 1980. Nos últimos anos, contudo, observam-se novas dinâmicas no município, como a formação do subcentro metropolitano de Laranjeiras ${ }^{2}$ e, especialmente, a proliferação de condomínios fechados horizontais e verticais.

Nesse contexto, emergem não apenas novas formas espaciais como também novos conteúdos do processo de urbanização da metrópole da Grande Vitória. A dinâmica do espaço urbano torna-se mais complexa na medida em que se desenvolve uma diversidade de formas de produção e de apropriação da cidade, o que não ocorre sem conflitos e contradições sociais. Com intuito de captarmos tais mudanças, particularmente no município de Serra, voltamos nossas atenções para os condomínios fechados, compreendendo-os como resultado de novas estratégias da produção imobiliária ${ }^{3}$ na cidade. Contudo, é preciso inserirmos essa problemática na totalidade que envolve a produção social do espaço urbano no período contemporâneo. Desse modo, buscamos apreender o fenômeno socioespacial, representado pela difusão dessas novas formas de moradia, como produto e, ao mesmo tempo, produtor da realidade urbana (GOTTDIENER, 1993).

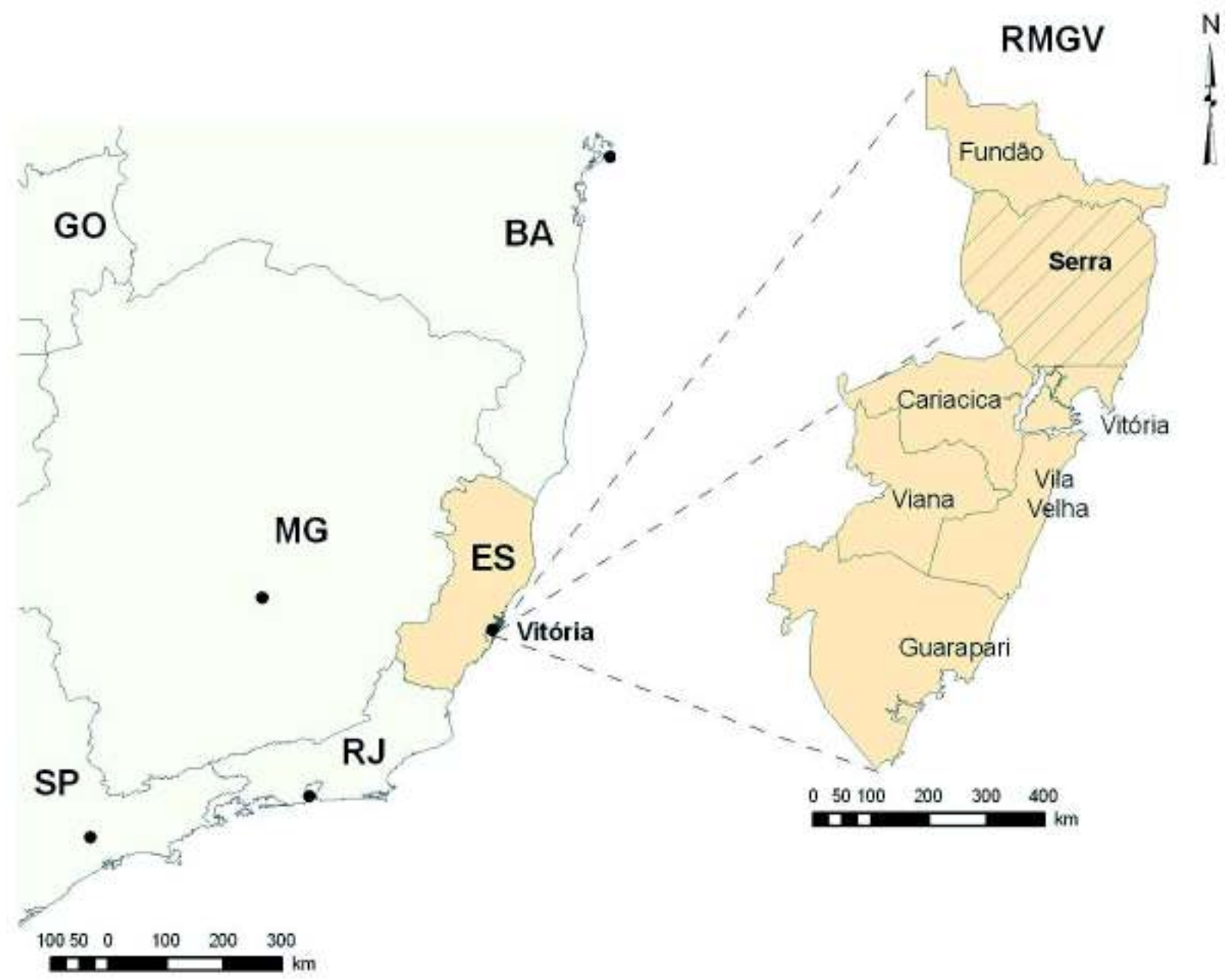

Figura 1 - Localização do município de Serra na Região Metropolitana da Grande Vitória (RMGV)

No quadro teórico, vários trabalhos apontam que a estruturação do espaço urbano, nas últimas décadas, tem se tornado cada vez mais complexa, tanto nas metrópoles como nas cidades médias. Uma das expressões desse novo momento é a produção de formas espaciais denominadas por Salgueiro (1998) de "enclaves". São formas espaciais, como um shopping center, centro empresarial 
ou condomínio fechado, que impõem uma diferença brusca entre elas e seu entorno imediato, o que engendra uma organização espacial da cidade marcada pela fragmentação. Assim, redefine-se “[...] o par centro-periferia, a partir da constatação de que há várias centralidades em definição e diferentes periferias em constituição (SPÓSITO, 2001, p. 86-87).

Para avançarmos nessa reflexão é preciso considerar a cidade como acumulação de tempos, como produto de relações sociais historicamente determinadas (CARLOS, 1994). A cidade, enquanto materialidade, expressa e, ao mesmo tempo, sustenta o processo de urbanização (SPÓSITO, 2001). Desse modo, tanto a organização espacial mais complexa como essas novas formas espaciais constituem-se em conteúdos da urbanização contemporânea. E, como afirma Lefebvre (2008), a urbanização contemporânea está articulada cada vez mais às possibilidades da acumulação em diferentes dimensões da realidade social, ampliando as contradições e conflitos sobre a produção social da cidade.

Nessa perspectiva, as possibilidades de acumulação para além da indústria ganham relevância, particularmente a partir da produção imobiliária apoiada no setor financeiro. Os incorporadores, como importantes agentes modeladores do espaço urbano (CORRÊA, 1989), recentemente têm engendrado novas estratégias no processo de produção e apropriação da cidade. De um lado, observa-se a difusão de novos produtos imobiliários e, por outro, a atuação da incorporação imobiliária em áreas tradicionalmente não atrativas para o setor (SPÓSITO, 2001; PEREIRA, 2009). As áreas periféricas passam a ser produzidas por novas relações, que se estabelecem também entre os "fragmentos" do espaço urbano.

\section{INDUSTRIALIZAÇÃO E PRODUÇÃO DO ESPAÇO URBANO DE SERRA COMO EXPANSÃO PERIFÉRICA DA METRÓPOLE DA GRANDE VITÓRIA}

Até o início dos anos 1960 a urbanização capixaba apoiou-se numa estrutura agroexportadora caracterizada pela pequena propriedade familiar, tendo o café como principal produto. A grande maioria da população vivia na zona rural. Dentro desse contexto, Bufon (1992) caracteriza essa urbanização como fraca, dispersa por todo o território e, ao mesmo tempo, concentrada na capital Vitória, principal núcleo urbano do Estado, em virtude do seu papel de sede político-administrativa e centro das atividades comerciais.

Esse quadro transformou-se radicalmente nas últimas três décadas do século XX. Apesar dos esforços industrializantes da elite local durante a década de 1960, o processo de industrialização no Espírito Santo se consolidou somente na segunda metade da década de 1970, com o advento dos chamados Grandes Projetos Industriais (CAMPOS JR, 2002). O desenvolvimento industrial que se concentrou na Grande Vitória resultou, em grande parte, de incentivos diretos do governo federal a partir do II Plano Nacional de Desenvolvimento (PND), que visava estimular a industrialização em áreas fora do eixo Rio-São Paulo. Outro elemento significativo foi o interesse de capitais externos em determinados setores, como o de semielaborados (pelotas de minério de ferro, aço e celulose). Assim, entre o final da década de 1970 e início dos anos 1980, grandes indústrias, como a Companhia Siderúrgica de Tubarão (atual Arcellor Mital) e a Aracruz Celulose (atual Fibria), iniciaram suas atividades.

A industrialização, somada às significativas transformações sofridas pelo campo capixaba durante os anos 1960 com o processo de erradicação dos cafezais, imprimiu novos conteúdos ao processo de urbanização. A partir do final da década de 1970, a urbanização passou a se vincular diretamente às necessidades da acumulação do capital industrial, o que não significou abandono das funções históricas da cidade de Vitória. Aliás, pelo contrário, em virtude das características particulares da industrialização capixaba ${ }^{4}$, tais funções foram reforçadas. Nesse contexto, o espaço urbano foi redefinido, tornou-se espaço metropolitano, conforme salienta Siqueira (2001, p. 93): 
O processo de industrialização veio a redefinir o espaço urbano na medida em que, somando-se ao papel de sede da burocracia e do capital comercial, a cidade também se constituiu no "lócus" da atividade produtiva. A Grande Vitória, como espaço metropolitano, além do centro político e do porto, sempre abrigou também as principais atividades regionais de caráter industrial, comercial, de serviços públicos, privados, culturais e financeiros $[\ldots]$

Como ocorreu com outras grandes cidades ou metrópoles brasileiras, a concentração de atividades econômicas na Grande Vitória, uma das características da metropolização desse espaço (ABE, 1999), veio acompanhada de um elevado crescimento demográfico, que tem ocorrido desde a década de 1960. Para se ter uma ideia, em 1960 a Grande Vitória abrigava 194.314 habitantes. Em 1991 esse número chegou a 1.064.919. Em 2000, já considerando a inclusão na Região Metropolitana da Grande Vitória (RMGV) dos municípios de Fundão e Guarapari, a população alcançou a cifra de quase 1 milhão e meio de habitantes. Portanto, nas últimas décadas do século passado a população do Espírito Santo se urbanizou e se concentrou na RMGV, como resultado do intenso fluxo migratório, ocorrido sobretudo nos anos 1970 e 1980 (CASTIGLIONI, 1994).

O processo de metropolização da Grande Vitória, segundo Abe (1999), não se expressa apenas a partir de mudanças quantitativas, como o crescimento demográfico e a expansão da mancha urbana em direção aos territórios dos municípios vizinhos da capital Vitória. Os conteúdos do processo de urbanização, alavancados pela lógica industrial, produzem um espaço urbano cada vez mais complexo e diferenciado.

Tendo como referência temporal sobretudo os anos 1970 e 1980, a dinâmica urbana da metrópole da Grande Vitória se "resume" em dois processos, que se articulam na totalidade da produção social da cidade: 1) verticalização da área central de Vitória e de porções norte e leste da capital e, posteriormente, da orla de Vila Velha, como resultado da apropriação do espaço urbano pela incorporação imobiliária, que se consolida a partir dos anos 1970;2) expansão periférica enquanto lugar onde a população migrante com menos recursos encontrou condições de se reproduzir, seja a partir de ocupações de áreas ambientalmente frágeis, de conjuntos habitacionais (financiados pelo antigo BNH) ou de loteamentos populares distantes das áreas mais bem servidas de infraestrutura. É articulado ao segundo processo que se desenvolve o tecido urbano no município de Serra.

Diferentemente do que ocorreu em Cariacica, Vila Velha e, especialmente, Vitória, que conheceram ainda nas décadas de 1950 e 1960 um significativo surto de urbanização ${ }^{5}$, no município de Serra a produção do espaço urbano resultou, quase que exclusivamente, do processo de industrialização, como foi comentado anteriormente. $\mathrm{O}$ território desse município, juntamente com a porção norte de Vitória, foi palco privilegiado de grandes plantas industriais, como a CST (atual Arcellor Mital) e a Companhia Vale do Rio do Doce (atual VALE), assim como de importantes equipamentos, tais como os portos de Tubarão e de Praia Mole. Além disso, o governo estadual implantou, um pouco mais ao norte, o Centro Industrial da Grande Vitória (CIVIT), setores I e II. Em virtude dessa concentração industrial e, principalmente, da elevada oferta de terra relativamente barata, o município, a partir da década de 1970, conheceu uma verdadeira explosão demográfica.

Em 1970, a população urbana de Serra não chegava aos 8 mil habitantes (Ver nota 5). Em 1991, a população da zona urbana já era superior a 220 mil habitantes, enquanto no último censo demográfico (IBGE), em 2000, esse número superou 320 mil. No período referido, portanto, a população do município foi multiplicada, aproximadamente, por 40 !

$\mathrm{O}$ acelerado crescimento demográfico de Serra articula-se a significativa oferta de moradia voltada para a população com poucos rendimentos. Desse modo, entre 1970 e 1990 os espaços da moradia no município se originaram de três formas: loteamentos populares (regulares ou irregulares), ocupações (invasões) e conjuntos habitacionais promovidos pelo Estado. O município de Serra foi o que abrigou o maior número de conjuntos habitacionais na Grande Vitória (Tabela 1).

[...] o município da Serra passou a ter um vertiginoso crescimento, implantando-se numerosos conjuntos residenciais e loteamentos em Carapina, nos platôs que ladeiam a BR 101 e a ES 010 [...]. 
Ocorreram também no planalto [sic] algumas ocupações irregulares em terrenos desfavoráveis à urbanização ou situação fundiária judicialmente conflituosa, de forma que os assentamentos subnormais são encontrados em encostas e nos fundos dos vales, na orla das lagoas, nos loteamentos não ocupados e em lotes de chácaras. (ABE, 1999, p. 384).

Tabela 1- Conjuntos habitacionais financiados pelo extinto BNH na Grande Vitória

\begin{tabular}{c|c}
\hline Municípios & $\mathrm{N}^{\circ}$ de unid. habitacionais \\
\hline Vitória & 4.526 \\
Vila Velha & 14.426 \\
Serra & $\mathbf{2 8 . 8 4 8}$ \\
Cariacica & 1.968 \\
Viana & 2.270 \\
Total & 52.038 \\
\hline
\end{tabular}

Fonte: COHAB-ES e INOCOOP-ES

Desde os anos 1970, o processo de urbanização tem se manifestado em Serra a partir de um extenso e descontínuo tecido urbano. Um espaço urbano espraiado, onde se intercalam áreas industriais, bairros populares e vastos vazios urbanos. O padrão espacial disperso da mancha urbana, além da lógica particular de produção da moradia na periferia (CAMPOS JR, 2008), teve como condicionantes importantes a estrutura viária e o sítio natural. Quanto ao segundo elemento, destaca-se o caráter recortado do espaço natural da porção leste do território de Serra, como pode ser atestado a seguir:

Nessa porção do território municipal predomina, em termos geomorfológicos, a Unidade dos Tabuleiros Costeiros. Os Tabuleiros Costeiros constituem-se em formas tabulares (topos planos), com a altimetria variando de 15 a 40 metros. Tais formas são recortadas por vales fluviais, cujos córregos deságuam em lagoas, como as lagoas Juara e Jacuném, e em rios como o rio Jacaraípe [...] (GONÇALVES, 2007, p. 44).

Em outras palavras, a produção do espaço urbano de Serra vincula-se à expansão da periferia da metrópole da Grande Vitória (ABE, 1999). Nesse sentido, as características da forma espacial, descritas anteriormente, não se constituem apenas no resultado de uma urbanização alavancada pelas necessidades da indústria, mas como condição para a realização desse processo histórico. Assim, além de suporte para a atividade industrial, Serra exerceu importante papel na reprodução da população trabalhadora que chegara à Grande Vitória em busca de empregos "prometidos" pela indústria:

A população atraída pelo novo perfil econômico do Estado, criado pelos grandes projetos, na sua grande maioria, teve dificuldade de se estabelecer em Vitória. Os terrenos apresentavam menor disponibilidade natural e social do que os da Serra, portanto eram mais caros. Resultado: a Serra teve papel importante, abrigando os migrantes, especialmente os de menor renda, que vieram para a Grande Vitória a partir de 1970 (CAMPOS JR, 2008, p. 10).

Portanto, o processo de industrialização na Grande Vitória engendrou um espaço metropolitano cuja característica marcante foi a expansão periférica. Serra, como vimos, teve parte de seu território apropriado por esse tecido urbano. Entretanto, nos últimos anos emergiram novas formas espaciais na metrópole da Grande Vitória, como os condomínios fechados construídos no município. Conforme discutiremos a seguir, esse processo evidencia novos conteúdos da urbanização, tornando o espaço metropolitano mais complexo e desigual na medida em que a produção imobiliária capitalista busca novos horizontes para sua valorização. 


\section{RECENTES TRANSFORMAÇÕES DO ESPAÇO URBANO DE SERRA E AS NOVAS POSSIBILIDADES DE VALORIZAÇÃO DO CAPITAL NO IMOBILIÁRIO}

O espaço metropolitano da Grande Vitória tem sofrido significativas mudanças, pelo menos desde o final da década de 1980, como ocorre em outras cidades ou metrópoles brasileiras. Nesse sentido, destacamos o processo de redefinição da centralidade intraurbana e a dinâmica imobiliária. Primeiramente, a produção do espaço metropolitano torna-se mais complexa a partir da emergência de novas centralidades no interior do município de Vitória e na escala metropolitana (REIS, 2007) ${ }^{6}$. Por outro lado, a dinâmica imobiliária, como elemento indissociável da produção da cidade, também expressa tais mudanças na metrópole e delas participa diretamente. Embora apresentados de maneira distintas, tais processos encontram-se articulados com a produção social do espaço urbano. Nesse texto, no entanto, privilegiamos a dinâmica imobiliária no município de Serra, onde se destaca a produção de novas formas de moradia, como os condomínios fechados horizontais e verticais.

A incorporação imobiliária, como expressão da produção capitalista do espaço construído, é resultado histórico da expansão das relações sociais de produção capitalista no setor da construção civil. No caso de Vitória, a construção por incorporação se consolidou nos anos 1970 como resultado da combinação de condições específicas da urbanização da Grande Vitória, impulsionada pela industrialização, e de condições favoráveis de financiamento imobiliário a partir de recursos administrados pelo antigo BNH (CAMPOS JR, 2002). Com isso, o processo de verticalização ganhou impulso a partir da década de 1970. A princípio, o centro de Vitória foi a porção que sofreu as maiores transformações, com a construção de edifícios voltados para a moradia ou serviços. A partir da segunda metade dos anos 1970, as áreas litorâneas do norte de Vitória passaram a ser transformadas pela incorporação imobiliária, promovendo a verticalização. Nesse contexto destacase o bairro Praia do Canto, que se tornou, ao longo das últimas décadas do século passado, local de moradia de classe média e de alto poder aquisitivo e consolidou uma importante centralidade intraurbana em Vitória (REIS, 2007).

Nas décadas de 1980 e 1990, apesar da instabilidade no ritmo das construções (algo característico do setor imobiliário), o processo de verticalização, promovido pela incorporação imobiliária, se estendeu pelas orlas de Vitória e Vila Velha. A verticalização da orla desse último município se desenvolveu, especialmente, na década de 1990, impulsionada pela inauguração da "Terceira Ponte", que ligou o litoral sul de Vila Velha à zona norte de Vitória, ou seja, às áreas próximas a Praia do Canto (IPES, 2005). Aliás, com isso estabeleceu-se uma continuidade espacial do processo de verticalização nos dois municípios (CAMPOS JR, 2005). Reis (2007, p. 75) afirma que esse contínuo tem como pivô o bairro Praia do Canto:

Ratifica-se, aqui, a importância da Praia do Canto como pivô de um vetor de expansão imobiliária que abrange os bairros de Jardim da Penha e Jardim Camburi, em Vitória, bem como os bairros da Praia da Costa, Praia de Itapoã e, mais recentemente, Itaparica, todos localizados na orla do Município de Vila Velha (REIS, 2007. p. 75).

Na década atual, sobretudo nos últimos anos, o setor imobiliário tem encontrado novas áreas na Grande Vitória (Figura 2). Nesse sentido, os lançamentos imobiliários no município de Serra chamam a atenção. Em 2007 e 2008, o município foi responsável por mais de 60\% do crescimento do número de lançamentos imobiliários registrados na Grande Vitória, segundo dados do Sinduscon-ES ${ }^{7}$. Desse modo, Serra tornou-se a mais recente frente de atuação do mercado imobiliário. No entanto, esse processo não é marcado apenas por um deslocamento espacial dos investimentos imobiliários, mas também por mudanças qualitativas na dinâmica imobiliária, na medida em que a expansão do setor em direção a esse município ocorre a partir de um novo produto imobiliário: os condomínios fechados horizontais e verticais (Figuras 3). 


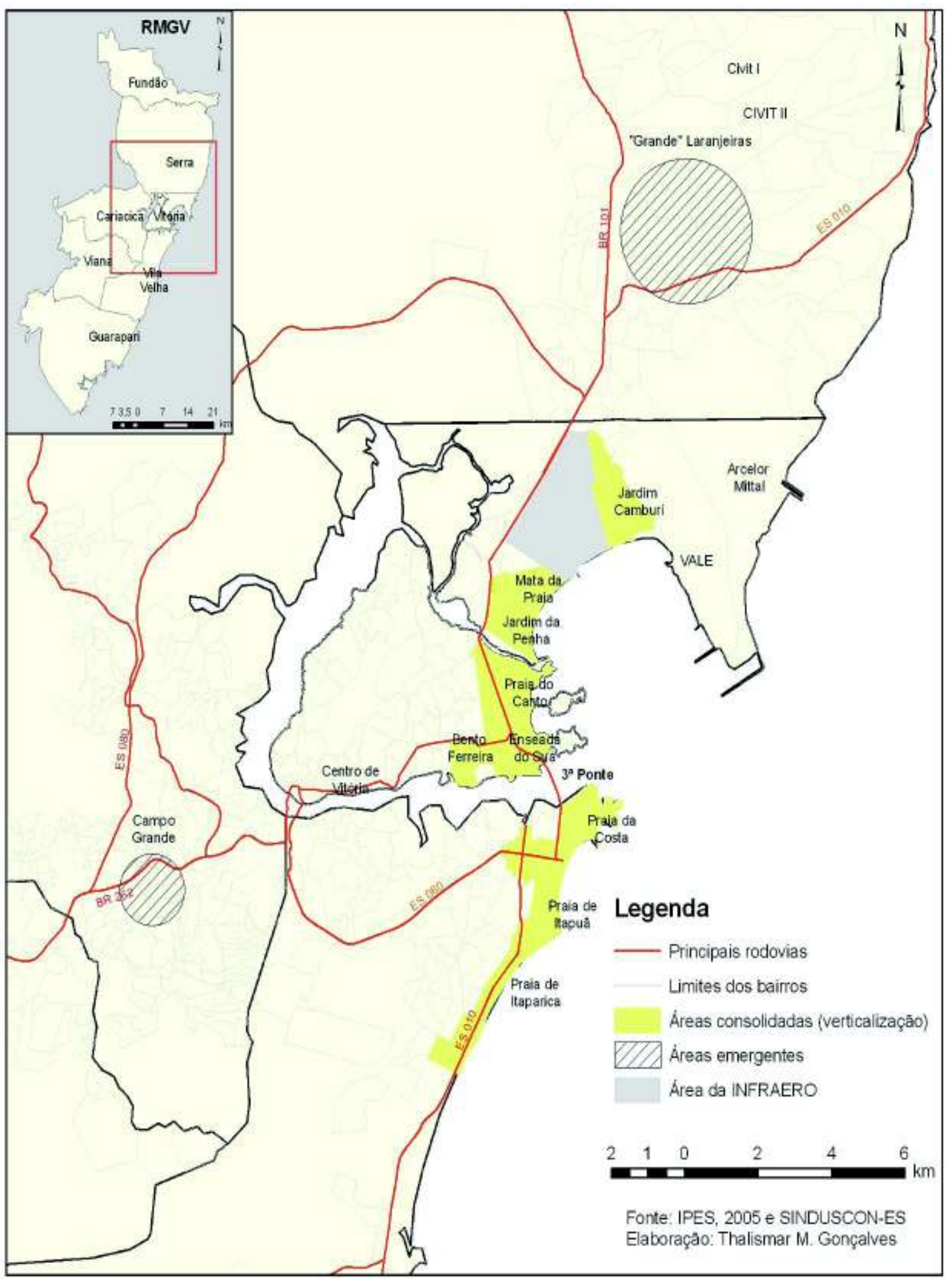

Figura 2 - Áreas consolidadas e áreas emergentes em relação à atuação da incorporação imobiliária na Grande Vitória. 


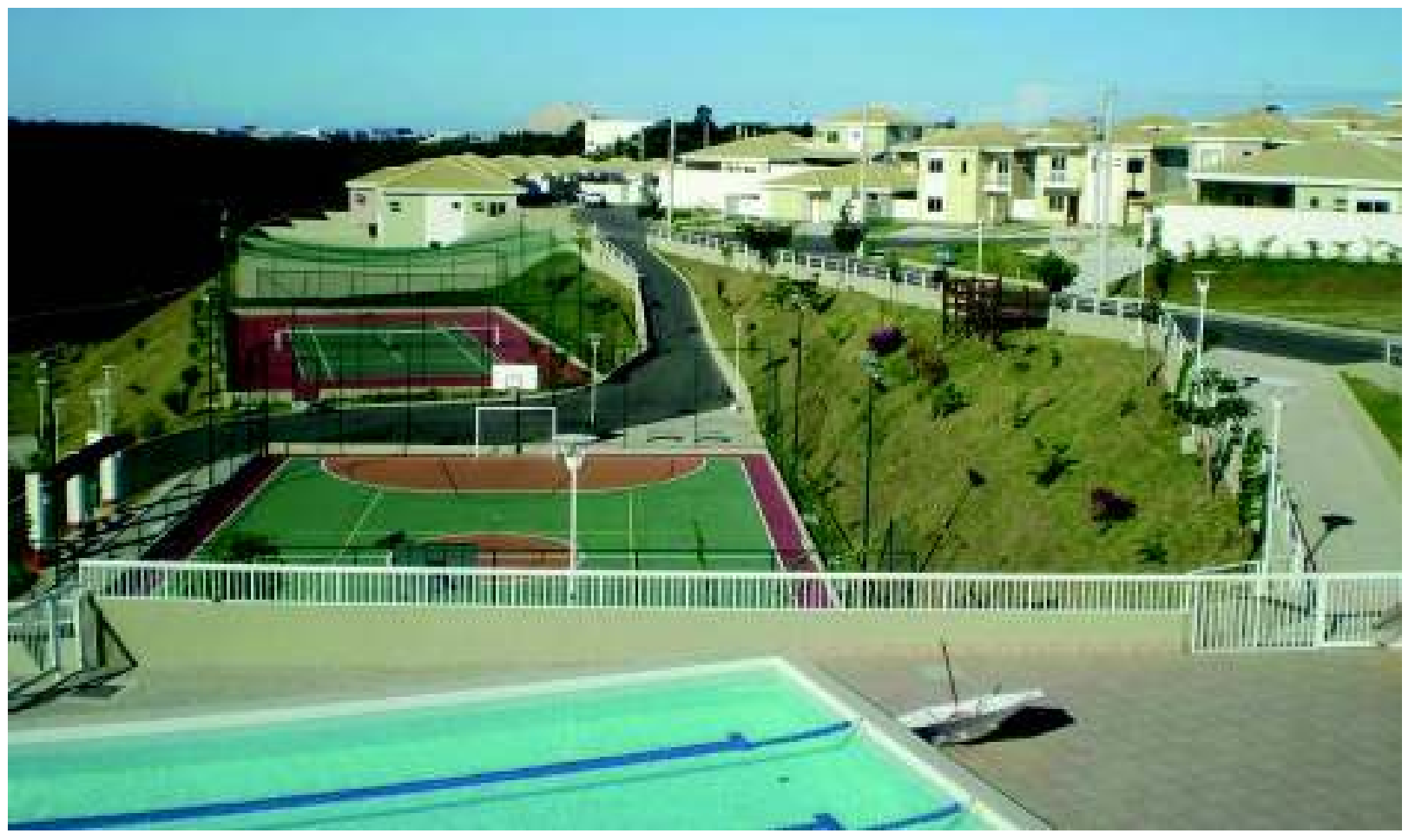

Figura 3 - Vista parcial do condomínio horizontal "Aldeia Parque" promovido pela parceria entre a "Paulista" Cyrela Realty do Brasil” e a empresa local Morar

Enquanto a incorporação imobiliária produz edifícios isolados nas orlas de Vitória e Vila Velha, no município de Serra o setor tem produzido agrupamentos de casas ou edifícios em amplos terrenos (murados e com aparato de segurança) providos de grande variedade de opções de lazer. Em vez do litoral, esses empreendimentos localizam-se nas proximidades de Laranjeiras (ver Figura 2), um importante subcentro metropolitano, que conta com um intenso comércio de rua como também grandes supermercados e um shopping center. No entanto, apesar da concentração no entorno de Laranjeiras, a tendência mais recente é o deslocamento de investimentos imobiliários também em direção ao litoral do município.

Além da particularidade relacionada ao produto imobiliário e à localização no espaço urbano, a dinâmica imobiliária em Serra tem sido promovida, especialmente, por um novo agente no setor imobiliário capixaba: grandes incorporadoras (de São Paulo, Rio de Janeiro ou Belo Horizonte) com capital aberto em bolsas de valores. Uma das formas mais comuns de atuação dessas incorporadoras é a de parcerias com empresas locais do ramo. Desse modo, observa-se uma subordinação das empresas menores, na medida em que essas entram no negócio como se fossem empreiteiras. A grande "fatia" dos resultados do negócio imobiliário é apropriada pelas empresas de fora, enquanto as locais recebem um ganho correspondente à construção realizada por administração.

Esse processo evidencia uma dinâmica imobiliária mais complexa na Grande Vitória, em que se observam novas estratégias da acumulação a partir da produção imobiliária. Esse processo, por sua vez, produz um espaço urbano em Serra cada vez mais fragmentado, o que revela o acirramento de uma urbanização voltada cada vez mais para os negócios, na acepção mais ampla possível (LEFEBVRE, 2008). Nesse cenário, os interesses do setor imobiliário, potencializado por novas formas de captação de recursos, se impõem de forma cada vez mais intensa e, ao mesmo tempo, extensiva sobre o território metropolitano. 


\section{CONSIDERAÇÕES FINAIS}

O processo de valorização da propriedade imobiliária no município de Serra se dá de forma diferente daquele que se verificou, e ainda se verifica, em Vitória e em Vila Velha. Aconteceu depois, e de outra maneira. O caráter periférico do município na Região Metropolitana, primeiramente, não foi fator de atração de capitais que buscassem valorização por intermédio da produção imobiliária.

Com a industrialização Serra tornou-se o lugar de moradia de trabalhadores para indústria e de população com menor poder aquisitivo. Em razão disso, a construção de moradias predominante se dava de forma espontânea (autoconstrução) e por promoção pública.

Sendo assim, a propriedade fundiária não possibilitava ganhos imobiliários capazes de viabilizar a produção imobiliária privada. Foi necessário que se criassem novas centralidades na Região Metropolitana e que Serra fizesse parte dessa nova estruturação espacial por meio do subcentro de Laranjeiras. Além desse caráter do processo de urbanização que se estende a partir de Vitória para o município vizinho, Serra, a construção também precisou sofrer mudanças para se apropriar do novo contexto.

A construção imobiliária introduziu no Espírito Santo o produto condomínio fechado no município de Serra. Um produto novo para as práticas então realizadas pelo mercado imobiliário em Vitória e Vila Velha.

Além do condomínio fechado, a experiência verificada em Serra deu-se por intermédio de incorporadoras de outros estados, capitalizadas com capital aberto em bolsa, realizando parceria com as empresas locais, que se sujeitaram à condição de empreiteiras, subordinadas às práticas das grandes empresas.

Do ponto de vista da disputa pelo território, houve uma mudança qualitativa importante. A promoção pública e a construção espontânea (autoconstrução) predominaram durante muito tempo enquanto formas de produção da moradia no município de Serra. Nesse contexto, essas duas formas de produção da cidade estabeleceram com o território de Serra um tipo de disputa que se condicionava a atender as necessidades de moradia de uma importante parcela da população, ainda que o padrão dessas moradias, seja dos conjuntos habitacionais, seja dos loteamentos populares, não fosse dos melhores; até mesmo porque se vinculava à possibilidade de reprodução da população com menos rendimentos, como já foi salientado. A situação hoje é todavia diferente, mais acirrada. A produção imobiliária em Serra serve ao negócio de atender a valorização do capital. A moradia deixou de ser produzida apenas para atender a necessidade do morador, voltando-se principalmente para a necessidade de valorização do capital.

Como a promoção dessas iniciativas ocorre por intermédio de empresas de fora, deslocou-se o nível decisório dos investimentos imobiliários em Serra para fora do Estado e elevou-se o nível das disputas por esse território, colocando uma outra dimensão de complexidade na gestão do seu território.

\section{NOTAS}

(1) A RMGV foi instituída oficialmente em 1995, com os municípios de Vitória, Vila Velha, Cariacica, Serra e Viana. Em 1999 e 2001, os municípios de Guarapari e Fundão, respectivamente, passaram a compor a RMGV.

(2) Ver Gonçalves (2007) e Campos Jr (2008).

(3) A produção imobiliária, aqui, refere-se à forma de construção por incorporação. Constitui-se a forma mais desenvolvida de produção capitalista do espaço construído (CAMPOS JR, 2002).

(4) A lógica da industrialização alavancada pelos "grandes projetos industriais" não teve a participação de capitais locais nesse processo; baseava-se numa produção em grande escala e voltada para o exterior. O processo de industrialização iniciado em São Paulo, ao contrário da situação capixaba, fundou-se na acumulação gerada regionalmente e depois estendida para outros estados do Sudeste, e a produção se direcionava para o mercado interno. 
(5) Em 1970, a população urbana de cada município da Grande Vitória: Vitória, 132.036; Vila Velha, 121.850; Cariacica, 69.200; Serra, 7.897; Viana, 1.620 (IBGE, 1970).

(6) O processo de redefinição da centralidade intraurbana não se refere apenas a emergência e consolidação de subcentros terciários, mas também a centralidades promovidas por grandes equipamentos de comércio e serviços, como os shopping centers e os hipermercados, e por prédios institucionais.

(7) Sindicato da Indústria da Construção Civil do Espírito Santo.

\section{REFERÊNCIA BIBLIOGRÁFICA}

ABE, André Tomoyuki. Grande Vitória, ES: crescimento e metropolização. Tese (doutorado) - Programa de Pós-Graduação em Arquitetura e Urbanismo, Universidade de São Paulo. São Paulo, 1999.

BUFFON, José Antônio. O café e a urbanização no Espírito Santo: aspectos econômicos e demográficos de uma agricultura familiar. Dissertação (Mestrado) - Programa de Pós-Graduação em Economia da Universidade de Campinas. Campinas, 1992.

CAMPOS Jr., Carlos Teixeira de. A construção da cidade: formas de produção imobiliária em Vitória. Vitória: Floricultura, 2002.

CAMPOS Jr., Carlos Teixeira de. História da construção e das transformações da cidade. Vitória: Cultural, 2005.

CAMPOS Jr., Carlos Teixeira de. Espaço urbano, habitação e uso do solo: Plano Estratégico de Serra 21- 2007-2027. Serra-ES, 2008. CD ROM. Disponível em: <www.serra-es.gov.br>. Acesso em: mai. 2009. CARLOS, Ana Fani Alessandri. A (re)produção do espaço urbano. São Paulo: Edusp, 2008.

CASTIGLIONI, Aurélia H. Processo de crescimento da Grande Vitória. Revista do Instituto Jones dos Santos Neves. Vitória, v. 7, n. 1, p. 9-10, dez. 1994.

IBGE. Censos Demográficos: 1950,1960,1970,1980,1991 e 2000. Dados disponíveis em: <www.ibge.gov. br>. Acesso em: 15 jan. 2009.

SINDUSCON-ES. Censos imobiliários. Disponível em: <www.sindicon-es.com.br>. Acesso em: mar. 2009. CORRÊA, R. L. O espaço urbano. São Paulo: Ática, 1989.

GONÇALVES, Thalismar M. A dinâmica do espaço urbano: um estudo sobre o bairro Parque Residencial Laranjeiras. Vitória-ES: Monografia de Geografia, Departamento de Geografia da UFES, 2007. GOTTDIENER, M. A produção social do espaço urbano. São Paulo:Edusp, 1993.

IPES. Verticalização e reestruturação urbana na Região Metropolitana da Grande Vitória: 1990-2002. Vitória, 2005.

LEFEBVRE, Henri. Espaço e política. Belo Horizonte: UFMG, 2008.

PEREIRA, Paulo Cesar Xavier. Transformações socioterritoriais de grandes áreas metropolitanas: metropolização e produção imobiliária, uma visão a partir de São Paulo. In: ENCONTRO DE GEÓGRAFOS DA AMÉRICA LATINA, 12, 2009. Montevidéu. Anais eletrônicos. Disponível em: <www.easyplanners. com>. Acesso em: jun. 2009.

SALGUEIRO, T. B. Cidade pós-moderna: espaço fragmentado. Revista Território. Rio de Janeiro, a. 3, n. 4, p. 39-53. 1998.

SIQUEIRA, Maria da Penha Smarzaro. Industrialização e empobrecimento urbano: o caso da Grande Vitória 1950-1980. Vitória: EDUFES, 2001.

SPÓSITO, Maria Encarnação B. A urbanização da sociedade: reflexões para um debate sobre as novas formas espaciais. In: DAMIANI, A. L., CARLOS, A. F. A. e SEABRA, O. C. DE L. O espaço no fim de século: a nova raridade. 2 ed. São Paulo: Contexto, 2001. p. 83-99.

Trabalho enviado em novembro de 2009

Trabalho aceito em dezembro de 2009 